\title{
FABRICATION OF NOVEL III-N AND III-V MODULATOR STRUCTURES 11 Fal BY ECR PLASMA ETCHING
}

S. J. Pearton ${ }^{(1)}$, C. R. Abernathy ${ }^{(1)}$, J. D. MacKenzie ${ }^{(1)}$, J. R. Mileham ${ }^{(1)}$,

R. J Shul ${ }^{(2)}$, S. P. Kilcoyne ${ }^{(2)}$, M. Hagerott-Crawford ${ }^{(2)}$,

F. Ren ${ }^{(3)}$, W. S. Hobson ${ }^{(3)}$ and J. M. Zavada ${ }^{(4)}$ :

${ }^{(1)}$ University of Florida, Gainesville FL 32611

${ }^{(2)}$ Sandia National Laboratories, Albuquerque NM 87185

${ }^{(3)}$ AT\&T Bell Laboratories, Murray Hill NJ 07974

${ }^{(4)}$ US Army Research Laboratories, RTP, NC 27709 .

\section{ABSTRACT}

Quantum well microdisk laser structures have been fabricated in the GaN/InGaN, GaAs/AlGaAs and GaAs/InGaP systems using a combination of ECR dry etching $\left(\mathrm{Cl}_{2} / \mathrm{CH}_{4} / \mathrm{H}_{2} / \mathrm{Ar}, \mathrm{BCl}_{3} / \mathrm{Ar}\right.$ or $\mathrm{CH}_{4} / \mathrm{H}_{2} / \mathrm{Ar}$ plasma chemistries respectively) and subsequent wet chemical etching of a buffer layer underlying the quantum wells. While wet etchants such as $\mathrm{HF} / \mathrm{H}_{2} \mathrm{O}$ and $\mathrm{HCl} / \mathrm{HNO}_{3} / \mathrm{H}_{2} \mathrm{O}$ are employed for $\mathrm{AlGaAs}$ and $\mathrm{InGaP}$, respectively, a new $\mathrm{KOH}$ based solution has been developed for AIN which is completely selective over both GaN and InGaN. Typical mask materials include $\mathrm{PR}$ or $\mathrm{SiN}_{\mathrm{X}}$, while the high surface recombination velocity of exposed AIGaAs $\left(-10^{5} \mathrm{~cm} \cdot \mathrm{sec}^{-1}\right)$ requires encapsulation with ECR-CVD $\mathrm{SiN}_{\mathrm{X}}$ to stabilize the optical properties of the modulators.

\section{INTRODUCTION}

Whispering gallery-mode microdisk lasers have optical modes strongly confined in a direction perpendicular to the wells comprising the disk ${ }^{(1)}$. Various methods have been reported for directional coupling of light output from these lasers, including patterned asymmetries in the shape of the microdisk resonators ${ }^{(2)}$, and use of a double-disk structure. ${ }^{(3)}$ A variety of different materials systems have been utilized to realize these low-threshold devices, including InGaAs/InGaAsP, ${ }^{(1-3)}$ InGaAs/InGaP, GaAs/AlGaAs ${ }^{(4)}$ and $\mathrm{ZnSe} / \mathrm{ZnCdSe}$ (5) $^{\text {(5) }}$

There is interest in the use of $\mathrm{GaN}$ and related alloys for blue/UV emitters and detectors, sparked mainly by the development of highly luminescent light-emitting diode. ${ }^{(6)}$ To date, the requisite dry and wet etching processes or indeed the growth of the necessary InGaN quantum wells have not been available to produce a microdisk structure in the nitrides. In this paper we report growth of a GaN-InGaN multiple quantum well layer structure by Metal Organic Molecular Beam Epitaxy (MOMBE), and a controlled two stage etching process for fabrication of a micro-resonator.

\section{EXPERIMENTAL}

The processing of the microdisck lasers is conceptually quite simple and is illustrated in Figure 1 for an optically pumped device. A photoresist, dielectric or metal mask is used during dry etching to form a $1.3 \mu \mathrm{m}$ high cylinder. A selective wet chemical etch (selective for

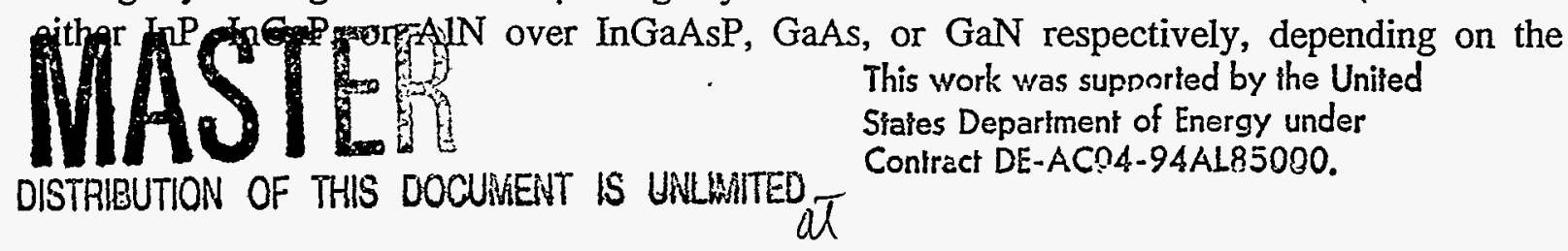


materials system being employed) is then used to undercut the material under the quantum wells, leaving a narrow support post which minimizes interference with generation of the whispering gallery modes around the top disk (see Figure 1 (c)).

For the GaN/InGaN system we need to perform a wet etch undercut to form the disk, but the normal substrate used for growth $\left(\mathrm{Al}_{2} \mathrm{O}_{3}\right)$ is extremely difficult to etch. To circumvent this, we grew the InGaN/GaN quantum wells on a AlN buffer layer $\sim 0.5 \mu \mathrm{m}$ thick. We then need to develop a selective wet etch for AlN over the GaN/InGaN.

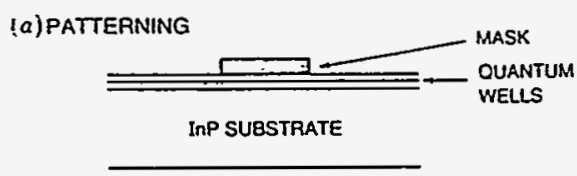

(b) DRY ETCH
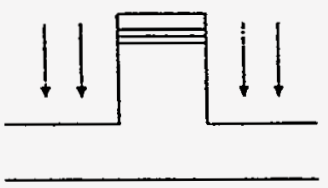

(c) WET CHEMICAL ETCH

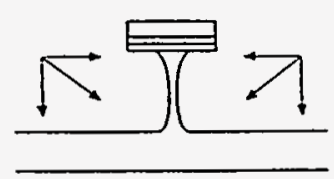

Figure 1. Schematic diagram of the process for fabricating an optically pumped microdisc laser.

\section{RESULTS AND DISCUSSION}

After lithographically patterning circular photoresist masks, microcylinders are formed by ECR plasma etching at $170^{\circ} \mathrm{C}$ in a $\mathrm{Cl}_{2} / \mathrm{CH}_{4} / \mathrm{H}_{2} / \mathrm{Ar}$ discharge (flow rates of $10,3,15$ and $10 \mathrm{sccm}$, respectively) at $1 \mathrm{mTorr}$ pressure and a microwave power of $850 \mathrm{~W}$. Additional rf power of $150 \mathrm{~W}$ was applied to the sample position to increase ion energy to $\sim 175 \mathrm{eV}$ and thereby improve etch anisotropy. These conditions produce smooth non-selective etching of all of the nitride layers in the structure, at rates between $~ 1,000 \AA / \mathrm{min}$ for AlN and $2200 \AA / \mathrm{min}$ for GaN.

We noticed that during lithographic patterning of AIN samples, exposure to AZ400K developer produced substantial etching. The active ingredient in the developer in regard to etching AlN is $\mathrm{KOH}$. A systematic study of the wet etching characteristics of AIN in AZ400K was performed to establish the rate-limiting step and dependence of etch rate on material quality.

Figure 2 shows Arrhenius plots of etch rate for three different samples. The etching is thermally activated with the same value of activation energy, $\sim 15.5 \pm 0.4 \mathrm{kcal} / \mathrm{mol}$, in all cases. Moreover, the rate was not sensitive to agitation and was dependent on the etchant concentration. These are characteristics of reaction-limited etching ${ }^{(7-9)}$ of the form

$$
\mathrm{R}=\mathrm{R}_{0} \exp (-\mathrm{E} a / \mathrm{kT})
$$

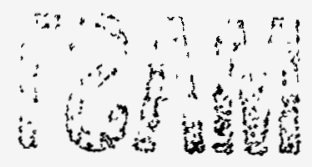


where $\mathrm{R}$ is the etch rate at temperature $\mathrm{T}, \mathrm{Ea}$ is the activation energy of the etch reaction, $\mathrm{k}$ is Boltzmann's constant, and $R_{0}$ is a constant which can be thought of as an attempt frequency for the reaction between $(\mathrm{OH})^{-}$ions and the AlN surface. we assume, therefore, that $\mathrm{R}_{0}$ is strongly dependent on material quality because the AIN with poorer crystallinity will have a greater number of weakened or defective bonds which are more susceptible to attack by the developer solution. Thus in our AIN, the absolute etch rate is governed by the crystalline quality of the epitaxial layer, but the etching has the same activation energy.

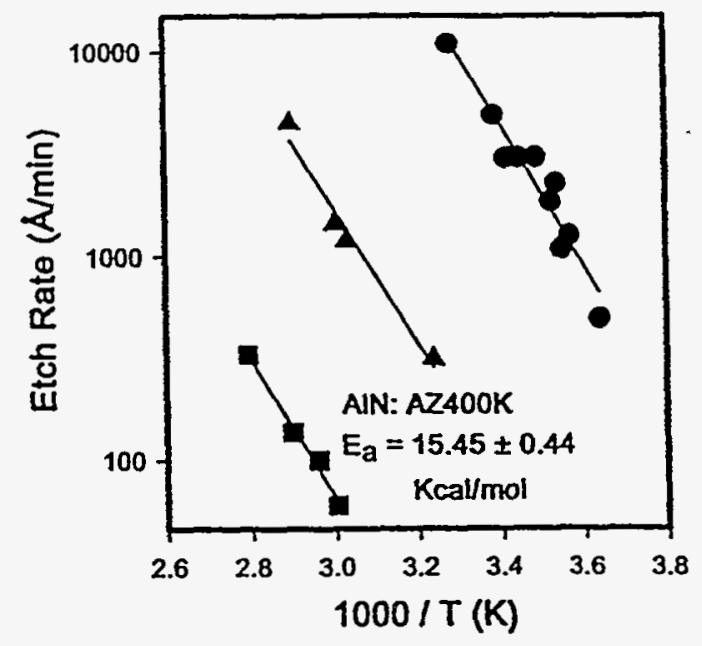

FIG. 2. Arthenius plot of etch rate of three different AIN samples in AZ400K. The polycrystalline AIN is denuted by $(\odot)$, while the singlecrystal data are denoted hy $(\boldsymbol{A})$ and $(\boldsymbol{Z})$. where the slowest etch rates were obtained for the higher quality AIN.

Figure 3 shows the time dependence of etch depth for the polycrystalline AIN in pure AZ400K solution and in a mixture of $5: 1 \mathrm{H}_{2} \mathrm{O}$ :AZ400K solution. There is a linear dependence in both cases and the etch rate was dependent on the etchant concentration which again is characteristic of rate-controlled, rather than diffusion-controlled, etch reactions. If the etch were the latter, one would expects a $t^{1 / 2}$ dependence for etch depth and an activation energy in the $1-6 \mathrm{kcal} / \mathrm{mol}$ range. ${ }^{(8)}$

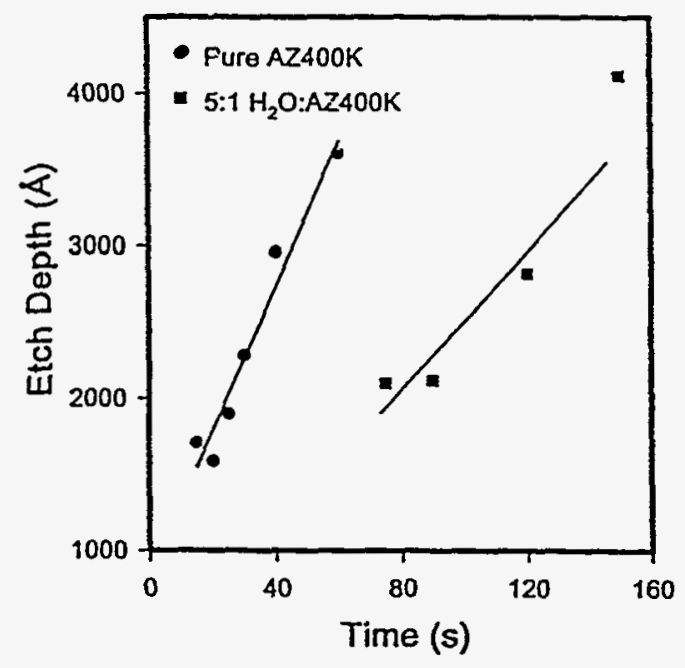

FIG.3. Time dependence of etch depth of a polycrystalline AIN sample in pure $A Z 700 \mathrm{~K}$ and in a $5: 1$ solution of $\mathrm{H}_{2} \mathrm{O}: \mathrm{AZ} 400 \mathrm{~K}$ at $23^{\circ} \mathrm{C}$. The etch rate is dependent on concentration as expected for rate-controlled etchants. 
In processing the microdisks, the AIN is then selectively wet etched in $A Z 400 \mathrm{~K}$ developer solution for $-30 \mathrm{~min}$. at $85^{\circ} \mathrm{C}$ to produce an undercut and leave the InGaN/GaN disk supported on an AIN pedestal. The active ingredient in the developer solution is $\mathrm{KOH}$ which etches AIN at a rate of $-330 \AA / \mathrm{min}$ at $85^{\circ} \mathrm{C}$. There was no measurable etching of $\mathrm{GaN}$ or InGaN under these conditions. We have found that the AIN wet etch rate is strongly dependent on the crystalline quality of the material, with much higher rates (up to $\sim \mu \mathrm{m} / \mathrm{min}$ for polycrystalline AIN Figure 4 shows an SEM micrograph of a typical microdisk after this two step etching procedure. It is important to note that other layer structures are also feasible, including use of AlGaN/InGaN quantum wells on a thick GaN buffer. However there have been no reports of a controlled selective etch for GaN with practical rates at this stage.

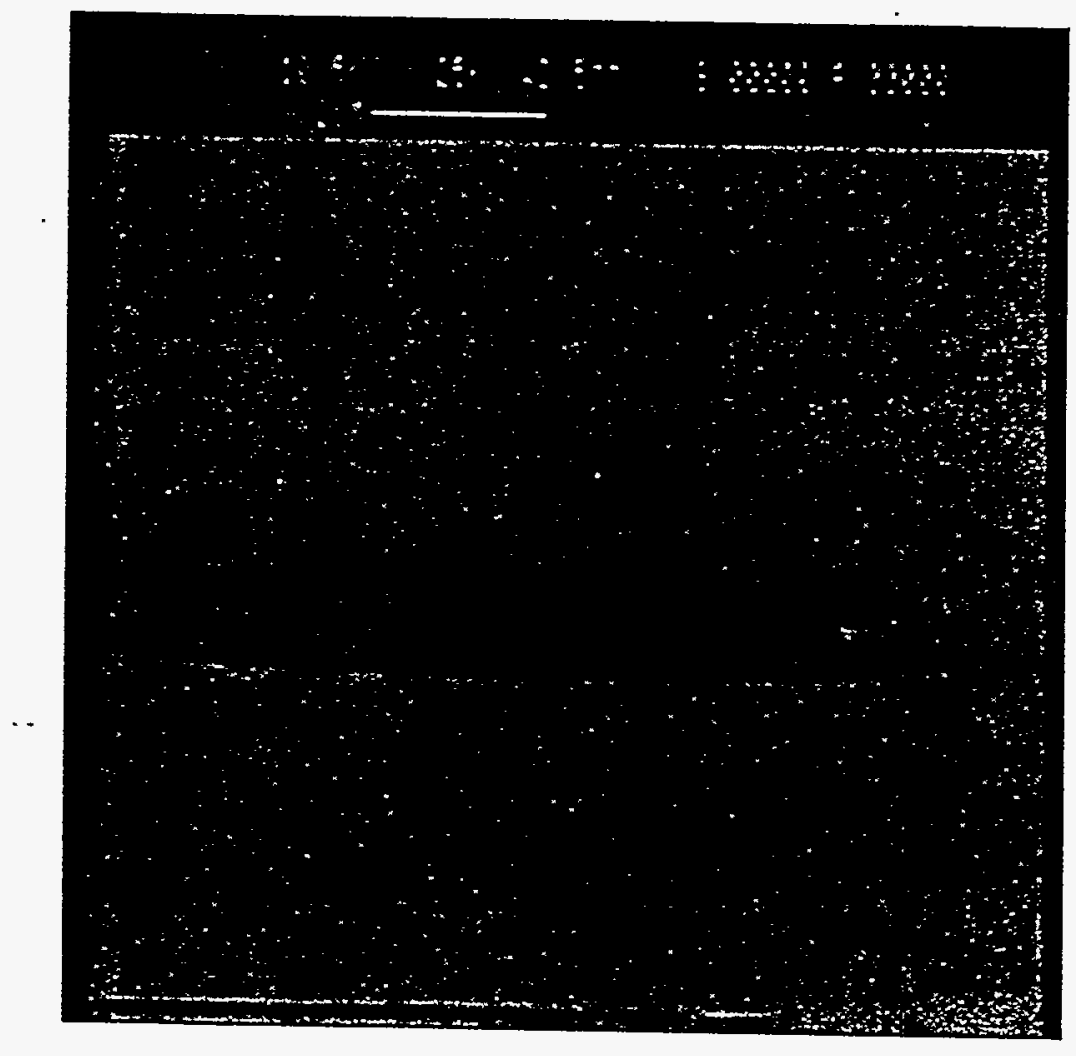

Figure 4. SEM micrugı apsz …..

To integrate a quantum wire laser on top of the microdisk is relatively straightforward, and this would allow the quantum wire laser to be pumped by the microdisk since emission from the latter is both within the plane of the quantum wells and vertically. A schematic of the process sequence is shown in Figure 5. After formation of the sidewalls, the microdisk laser is created by a combination of dry and wet etching, and then the quantum wire laser fabrication is completed using the sidewalls as an etch mask.

While the microdisk laser structures generally operate well without the need for surface passivation, AlGaAs for example is known to be prone to oxidation and therefore to degraded surface characteristics. This is a particular problem for laser facets ${ }^{(10)}$ or for surface recombination near the base-emitter junctions of HBTs, especially for small emitter dimensions. $^{(11)}$ 

TABLE I. Surface recombination velocities (in $\mathrm{cm}^{-} s^{-1}$ ) for InGaP and AlGaAs $p-n$ junction samples as a function of their processing treatments.

\begin{tabular}{rcccc}
\hline & Initial & $250^{\circ} \mathrm{C}, 60 \mathrm{~min}$ & $5 \mathrm{~F}_{5}$ & $\left(\mathrm{NH}_{4}\right)_{2} \mathrm{~S}_{x}$ \\
\hline InGaP & & & & \\
Wet etched & $4.4 \times 10^{4}$ & $4.9 \times 10^{4}$ & $4.6 \times 10^{4}$ & $2.2 \times 10^{4}$ \\
Dry etched & $5.2 \times 10^{4}$ & $5.1 \times 10^{4}$ & $4.9 \times 10^{4}$ & $2.6 \times 10^{4}$ \\
AlGaAs & & & & \\
Dry etched & $9.0 \times 10^{4}$ & $9.1 \times 10^{5}$ & $8.4 \times 10^{5}$ & $3.7 \times 10^{4}$ \\
\hline \hline
\end{tabular}

\section{ACKNOWLEDGMENTS}

The work at UF is partially supported by an ARO AASERT grant and a DOD URI administered by AFOR.

\section{REFERENCES}

1. S. E. McCall, A. F. J. Levi, R. E. Slusher, S. J. Pearton and R. A. Logan, Appl. Phys. Lett. 60289 (1992).

2. A. F. J. Levi, S. L. Slusher, J. L. Glass, S. J. Pearton and R. A. Logan, Appl. Phys. Lett. 62 561 (1993).

3. D. Y. Chu, M. K. Chin, W. G. Bi, H. Q. Hou, C. W. Tu and S. T. Ho, Appl Phys. Lett. 65 3167 (1994).

4. U. Mohideen, W. S. Hobson, S. J. Pearton, F. Ren, and R. E. Slusher, Appl. Phys. Lett. 65 1911 (1994).

5. M. Hovinen, J. Ding, A. V. Nurmikko, D. C. Grillo, J. Han, L. He and R. L. Gunshor, Appl. Phys. Lett. 623128 (1993).

6. S. Nakamura, T. Mukai and M. Senoh Appl. Phys. Lett. 641687 (1994).

7. S. S. Tan, M. Ye and A. G. Milnes, Solid State Electron. 3817 (1995)

8. S. K. Ghandi, VLSI Fabrication Principles (Wiley, New York, 1994).

9. W. M. Moreau, Semiconductor Lithography: Principles, Practices and Materials (Plenum, New York, 1988).

10. J. L. Jewell, S. L. McCall, Y. H. Lee, A. Scherer, A. C. Gossard and J. H. English, Appl. Phys. Lett. 541400 (1989).

11. H. H. Lin and S. C. Lee, Appl. Phys. Lett. 48839 (1985).

\section{DISCLAIMER}

This report was prepared as an account of work sponsored by an agency of the United States por their Government. Neither the United States Government nor ans agency legal liability or responsiemployees, makes any warranty, express or implied, or assumes any legal liability or reduct, or bility for the accuracy, completeness, or usefulness of any information, apparatus, product, or process disclosed, or represents that its use would not infringe privately owned rade, trademark, ence herein to any specific commercial product, process, or service by trade narsement, recommanufacturer, or otherwise does not necessarily constitute or imply its endoreof. The views mendation, or favoring by the United States Government or any agency thecof. The of the and opinions of authors expressed herein do not necessarily state or reflect those of the United States Government or any agency thereof. 